\title{
A SYSTEM BIOLOGY APPROACH TO DISCERN THE NATIVE BIOCHEMICAL FUNCTION OF HG METHYLATION \\ PROTEINS IN DESULFOVIBRIO DESULFURICANS ND132
}

CAITLIN M. GIONFRIDDO ${ }^{1}$, REGINA L. WILPISZESKI ${ }^{1}$, ANN M. WYMORE ${ }^{1}$, MIRCEA PODAR ${ }^{1}$, ALLISON SOREN ${ }^{2}$, CYNTHIA C. GILMOUR ${ }^{2}$, DWAYNE A. Elias ${ }^{1}$

${ }^{1}$ Oak Ridge National Laboratory, Oak Ridge, TN USA (gionfriddocm@ornl.gov)

${ }^{2}$ Smithsonian Environmental Research Center, Edgewater, MD USA

The $h g c A B$ gene pair encodes $\mathrm{Hg}$ methylation capability in anaerobic microorganisms Biomethylation does not provide benefit to the cell, and deletion of $h g c A B$ does not appear to hinder growth or produce any major phenotype. It is postulated that the native function of $\mathrm{Hg}$ methylation proteins $(\mathrm{HgcAB})$ is not $\mathrm{Hg}$ methylation, but the methylation of an unknown metabolite(s). $\mathrm{Hg}$ methylation has been linked to one-carbon metabolism for acetyl-CoA and methionine biosynthesis, sometimes as part of the Wood-Ljundahl pathway, yet a specific biochemical pathway remains elusive. Here we take a systems biology approach to exploring the physiological function of $\mathrm{HgcAB}$ using Desulfovibrio desulfuricans ND132 as a model organism. For this study, we compared growth and metabolite profiles of various $D$. desulfuricans ND132 gene deletion strains related to carbon and $\mathrm{Hg}$ cycling to the wild- type. Mutant strains (e.g. $\Delta h g c A B, \Delta m e t H, \Delta c o b T)$ that exhibited differences in $\mathrm{Hg}$ methylation capability compared to wild-type (e.g. 0-246\%) were grown in defined media with various substrates (e.g. pyruvate, fumarate, lactate, sulfate, formate, acetate). Organic acid, anion, and metabolite concentrations were monitored throughout the growth of the cells to determine if changes in central metabolism coordinated to changes in $\mathrm{MeHg}$ generation between wild- type and mutant strains. Indeed, significant differences in substrate consumption, acetate and biomass production, and gene transcription were observed between the strains under fermentative and sulfate- reducing conditions using transcriptomics, proteomics, metabolomics and lipidomics. A genome-scale metabolic model of Desulfovibrio desulfuricans ND132 using multi-omics analyses indicates that deletion of $h g c A B$ results in changes to carbon substrate utilization and compensatory gene regulation to compensate for the loss of $\mathrm{HgcAB}$. Understanding this native contribution of $\mathrm{HgcAB}$ to cellular metabolism will help predict the environmental conditions and metabolic states that control distribution and activity of $\mathrm{Hg}$-methylating bacteria while aiding in the accuracy of hydrobiogeochemical models of Hg-methylation currently being constructed. 